\title{
Exploring Automated Leadership and Agent Interaction Modalities
}

\author{
Douglas C. Derrick \\ University of Nebraska Omaha \\ dcderrick@unomaha.edu
}

\author{
J. S. Elson \\ University of Nebraska Omaha \\ jselson@unomaha.edu
}

\begin{abstract}
Advances in computer technology and research in the field of artificial intelligence have enabled computers to take on roles traditionally held by humans. Insights from leadership research have identified behaviors that, when applied strategically and systematically, can improve individual and team performance. We propose that some aspects of leadership are candidates for automation. This paper briefly reviews relevant leadership literature and describes three leadership behaviors that may be possibly automated: goal setting, performance monitoring, and performance consequences. The paper also explores the relationship of different embodiments of the artificial leaders, the impact of these embodiments in conveying social presence and the impact of this presence on performance and satisfaction outcomes. We conducted an experiment to investigate the effect of automated leadership on follower attitudes and behavior. Initial results suggest that automated leadership may positively influence performance and accuracy for individuals engaged in a clerical task.
\end{abstract}

\section{Introduction}

Would you follow orders from an intelligent machine leader? This question and a number of related aspects of automated leadership were explored in an episode from the sci-fi television series, Star Trek The Next Generation. In the fifth season, an intelligent humanoid robot named Data takes command of the USS Sutherland and a human crew. While originally science fiction, advances with artificial intelligence and computing may result in an intelligent computer agent leading human teams in a similar way. The next generation of automated information systems will utilize human-like communication and the interpretation of both verbal and non-verbal messages [19, 23, 67].

Definitions of leadership abound. In a review of leadership research, Stogdill [74] highlights that there are almost as many definitions of leadership as those who have tried to define it. In this current work, we define leadership as "a process whereby an individual influences a group of individuals to achieve a common goal" [65]. Two broad categories of leadership are highlighted in the literature, transformational and transactional leadership. Transformational leadership is one such category, and often relates to charismatic individuals creating a vision for the future and challenging the status quo $[6,16,62]$. Transformational leadership has a number of weaknesses [65, 78] making it unfit for a number of situations. Sometimes transactional leadership is required. Transactional leadership is another category of leadership that deals more with the execution and establishment of systems and processes related to goals and plan implementation [18, 54]. Transactional leaders exchange things of value with subordinates to advance their own and their subordinates' agendas [46, 47, 75].

In this paper, we focus on transactional leadership and propose that this form of leadership can be implemented in various intelligent automated systems. While previous studies have investigated human-agent teams and the role of human leaders, this present effort looks to explore various aspects of an artificially intelligent machine and its capabilities to provide limited leadership in a clerical work task. We first provide background related to automated leadership including a discussion around goal setting, performance monitoring, and performance consequences. Next, we discuss social presence and look at how this construct may manifest itself across four leader agents modalities. We propose to automate three leadership behaviors and explore the social presence of the automated leader as a moderating variable. Finally, we present results from an experiment comparing attitudes and performance of individuals lead by an intelligent agent to individuals completing the same task without leadership. 


\section{Background}

At the macro-level, this research paper proposes to examine the relationship between automated leadership, social presence and task performance, and follower satisfaction. Figure 1 shows the proposed relationships between each of these constructs. The very essence of leadership is to improve performance and develop followers. Leadership theories posit that that leadership consists of behaviors that should be applied strategically and systematically to motivate individuals and teams to perform [2, 24, 36, 42, 52, 76, 79].

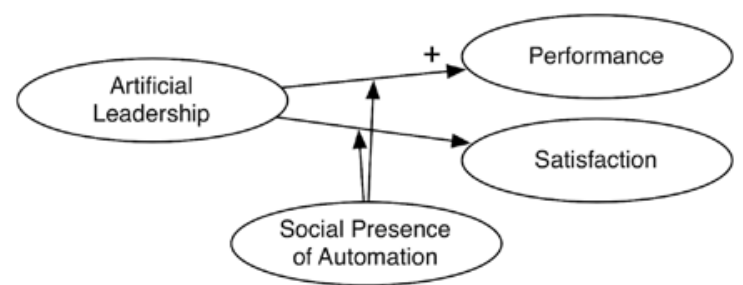

Figure 1. Basic Research Model

\subsection{Automated Leadership}

There are multiple supervisory behaviors that have shown a positive impact on performance [27, 44]. We propose to apply an automated leadership style, which highlights the importance of certain behaviors, such as providing information and developing goals [38]. Research in virtual teams has shown that effective leaders in distributed teams are extremely efficient at providing regular, detailed, and prompt communication with their peers and in articulating role relationships (responsibilities) among the virtual team members [41]. Three leadership behaviors have been selected for automation: goal setting, performance monitoring, and performance consequences.

2.1.1. Goal Setting. A goal is a desired state or outcome [49]. According to Locke and Latham [49], goals affect performance through four mechanisms. First, they serve a directive function. Second, goals have an energizing function. Third, goals affect persistence. Fourth, goals affect action indirectly by leading to the arousal, discovery, and/or use of taskrelevant knowledge and strategies. Locke and Latham [49] showed that the highest and most difficult goals produced the highest levels of effort and performance. They also found that specific, difficult goals led to consistently higher performance than urging people to do their best. Atkinson [5] showed that there was an inverse, curvilinear relationship between task difficulty (measured as probability of success) and performance. The highest level of effort occurred when the task was moderately difficult. Therefore, effective leaders will set goals of appropriate difficulty to stimulate the optimal performance according to a given team's capability. For the ad hoc nature of this leader and follower experiment, effective goal setting involves formulating specific, challenging and time-constrained objectives [11].

2.1.2. Performance Monitoring. Antonakis, Avolio and Sivasubramaniam [3] noted that transactional leadership is the ability to control and monitor outcomes. Research by Larson and Callahan [48] looked at the role of monitoring on performance. They hypothesized that performance monitoring would have an independent effect upon work behavior and found that monitoring improved subjects work output independent of other factors. Similarly, Brewer [14] found that the quantity of work improved when monitored. Aiello and Kolb [1] examined the role of electronic performance monitoring and social context on productivity and stress. They found that individually monitored participants were vastly more productive than those monitored at the group level for a simple task. More recent research has evaluated how electronic performance monitoring systems impact emotion, performance, and satisfaction [39, 63].Therefore, effective leaders will actively monitor the performance of individual team members and the team as a whole.

2.1.3. Performance Consequences. Bass [9] argued that theories of leadership primarily focused on follower goal and role clarification and the ways leaders rewarded or sanctioned follower behavior. Similarly, Larson and Callahan [48] found that monitoring along with consequences (feedback to the subjects about their performance during the task) significantly increased subjects' work output and that this provided the largest increase in productivity. Thus, how well a leader is able to monitor performance and influence the team's behavior is a measure of transactional leadership ability. Follower behavior can be shaped by effectively providing feedback and appropriate consequences. Consequences can be defined as either motivating/reinforcing events or as disciplining/punishing ones [4, 51]. Komaki et al. [44] expanded this definition to include consequences that are neutral and informational in character. For this study, we use their definition of performance consequences, which is defined as communicating an evaluation of or indicating knowledge of another's performance, where the indication can range from highly evaluative to neutral. This type of 
communication is vital for performance and compliance [45, 71] . An artificial system can operate by creating clear structures that make it certain what is required of the subordinate team members, and the rewards that they will receive for following instructions. Punishments can also be clearly stated and then a computer system can be coded to use operant conditioning on followers. Komaki provides several examples of positive, negative, and neutral consequences. Several examples are listed below:

\section{Positive}

- "You have done good work; no signs of errors!"

- "Great, you have done it so quickly."

Negative

- "You have made a great deal of errors."

- "Oh no. You have done this all wrong." Neutral

- "You have over 300 open cases."

- "He made a call yesterday for those materials."

\subsection{Social Presence}

Social presence is the sense that one is together with another. It encompasses the idea that embodied agents have a persona that causes natural reactions from human beings. Heeter [34] said that this phenomenon relates to the apparent existence of and feedback from the other entity in the communication and that social presence is the extent to which other beings in the world appear to exist and react to the user. Biocca, Harms and Burgoon [12] posit that social presence may be the byproduct of reading or simulating the mental states of virtual others and that social presence is related to the theory of the mind. They state that when users interact with agents or robots, they "read minds" and respond socially, even when they know that no mind or social other really exists. They continue that although humans know that the "other" is just ink on paper or patterns of light on a screen, the social responses are automatic [12]. Similarly, Computers as Social Actors (CASA) theory proposes that human beings interact with computers as though computers were people [61]. In multiple studies, researchers have found that participants react to interactive computer systems no differently than participants react to other people [59]. It is suggested that people fail to critically assess the computer and its limitations as an interaction partner [57] and as a result, the norms of interaction observed between people occur no differently between a person and a computer [33]. CASA has been used in multiple studies to provide structure for experimentation. Some similar studies include instances were computers have been specifically designed to praise or criticize performance [60], to display dominant or submissive cues [58], to flatter participants [25], or to display similar or dissimilar interaction cues with participants [56]. More recent studies have shown how individuals may form group relations with computer agents [77], how social presence affects interaction in a virtual environment [32], and that social presence factors contribute significantly to the building of the trustworthy online exchanging relationships [50].

\subsection{Agent Modalities}

Various agent modalities may impact the perception of social presence by enabling more information rich experiences. Information richness can be defined as "the ability of information to change understanding within a time interval” [17]. Information richness is at the heart of Media Richness Theory, which is a framework developed by Daft and Lengel that looks at the properties of different media to communicate information. Daft and Lengel [17] provide examples of different communication modes stating that face to face is the most rich, followed by telephone and personal letters, and ending with impersonal writing and numerical documents being the least rich mediums. Social Presence Theory is related to Media Richness Theory in that face-to-face communication may enable more presence than other text-based mediums. We turn next to a discussion of four interaction modalities we considered for the automated leader.

2.3.1 Text-based agent. One level of interaction for the automated leader is simply to send a text-based message. Each of the leadership behaviors described above can be put into an agent that is "unembodied" and communicates with the follower through text messages that appear on the screen. Social presence can be achieved through simulating interaction with another real person [35]. Trust in technology also depends upon machine accuracy, responsivity, predictability, and dependability [55]. With text-based agents social presence can also be enhanced by increasing perceptions of agent responsiveness. Responsiveness, defined by Schuetzler et al. [72] as the "ability of the agent to provide responses contingent on user messages.” Utilizing various data inputs (such as responses text, environmental sensors or cameras) an automated agent can tailor responses to increase perceptions of responsiveness. We anticipate that this lowest level of presence will moderate both performance and satisfaction and should provide greater performance than no leadership at all. 
2.3.2 Embodied two-dimensional agents. The next level of presence for the adaptive intelligent agent in our experiment will be a "flat", embodied agent. The primary means the automated leader has for affecting its follower are the signals and messages it sends to the human via its rendered, embodied interface. For this paper, embodied agents refer to virtual, threedimensional human likenesses that are displayed on computer screens. While they are often used interchangeably, it is important to note that the terms avatar and embodied agent are not synonymous. If an embodied agent is intended to interact with people through natural speech, it is often referred to as an Embodied Conversational Agent, or ECA [68]. The signals available to the agent take on three primary dimensions, which are appearance, voice, and size. The appearance can be manipulated to show different demeanors, genders, ethnicities, hair colors, clothing, hairstyles, and face structures. One study of embodied agents in a retail setting found a difference in gender preferences. Participants preferred the male embodied agent and responded negatively to the accented voice of the female agent. However, when cartoonlike agents were used, the effect was reversed and participants liked the female cartoon agent significantly more than the male cartoon [53].

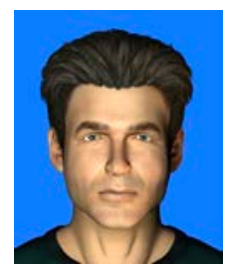

Figure 2. Sample Flat Automated Agent

Agents that are photorealistic need to be completely lifelike, with natural expressions, or else individuals perceive them negatively, and a disembodied voice is actually preferred and found to be clearer. When cartoon figures are utilized, three-dimensional characters are preferred over two-dimensional characters and whole body animations are preferred over talking heads [17]. Emotional demeanor is an additional signal that can be manipulated as an effector by the automated leader based on its desired goals, probable outcomes, and current states. The emotional state display may be determined from the probability that desired goals will be achieved. Emotions can be expressed through the animation movements and facial expressions, which may be probabilistically determined, based on the agent's expert system [18]. There are limitless possible renderings that may influence human perception and affect the agents operating environment. Derrick and Ligon [21] showed that these types of agents could use influence tactics such as impression management techniques to change user perceptions of the automation. Moreover, it has been shown that these perceptions change user/follower behavior including how people speak and interact with the agent [70]. Finally, Nunamaker and colleagues review how these types of agents have been tested and deployed in various contexts [66].

2.3.3 Hologram-based agents. An alternate technology that is widely deployed in interactive entertainment environments is a projection display known as Pepper's Ghost. While often referred to in the mainstream media as a hologram, this is a form of 2D display technology that creates an illusion of depth under limited viewing conditions and angles. Technological advancements have produced impressive visualizations and immersive experiences, as evidenced by recent highly publicized "live" stage performances by celebrities who are not present (e.g. Narendra Modi), animated characters (e.g., Hatsune Miku, Madonna with the Gorillaz), and digital recreations of deceased celebrities (e.g., Tupac, Michael Jackson). We have developed a prototype limited viewing angle pseudo-hologram (LVAH) based system from readily available 2D COTS systems to use as the automated leader with the most social presence. We propose that the more socially present leader that is created using a LVAH will moderate performance and satisfaction of the followers. Figure 3 shows the embodied hologram agent that will be used in the study.

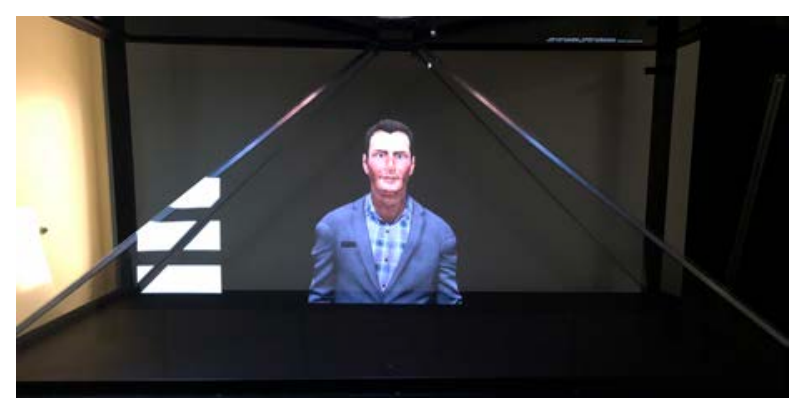

Figure 3. Embodied Hologram Leader Agent

2.3.4 Humanoid robotic agents. The term humanoid robot can be used to describe machines that are built with capabilities and physical features similar to the human body [37]. Humanoid robots occupy a shared physical space and are capable of interacting directly with objects located in their immediate environment. These robots come in various sizes ranging from small desktop sized machines to versions that are larger than 
an adult human. In addition to using natural language interaction and various body gestures, cameras allow the gaze of the robot to follow human teammates as they move about their environment. These characteristics of the humanoid robotic agent, along with the physical resemblance of the human body, may result in perceptions of social presence similar to agents utilizing the holographic embodiment modality. Figure 4 shows the humanoid robotic agent that will serve as our fourth agent leader condition.

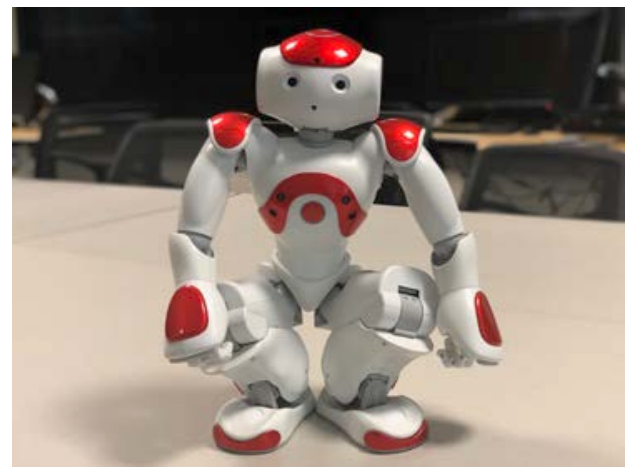

Figure 4. Robotic Leader Agent

\section{Method}

Graduate and undergraduate students from a Midwestern university were recruited to participate in this study and were compensated with course credit for their involvement. The initial study involved 36 individuals who completed the task in either a textbased leader condition or a no leader condition. Our final data set eliminated two individuals ( $<10 \%$ of total sample) who failed to complete the experimental task. We measured the followers' perceptions of social presence in both conditions.

We created a task where students input fictional alumni information into an online system. We generated 500 fictional names, addresses and phone numbers, and printed them out on sheets of paper. Participants were told, "We are capturing addresses and contact information for recent UNO Alumni that will be used to send information, fundraise, and help build the UNO community. In front of you, there is a sheet of alumni's information that must be input into the system. Please use the data entry screen on the computer to input this data. Work as quickly and as accurately as possible, as your performance is based on both the number and quality of the data that you have captured. After you have input each person's contact information, please press the submit button to store it to the database. You will input data for thirty minutes and then we will ask you about your experience”. The students then input the data for thirty minutes and were thanked for their participation.

Based on results obtained from a control group, the average user could input approximately 26 names in 30 minutes (25.7) with a standard deviation of 4.9. We measured the accuracy of the data input against the gold standard of the generated names stored in the database by comparing each field entered to the actual data. Figure 5 shows the user input screen.

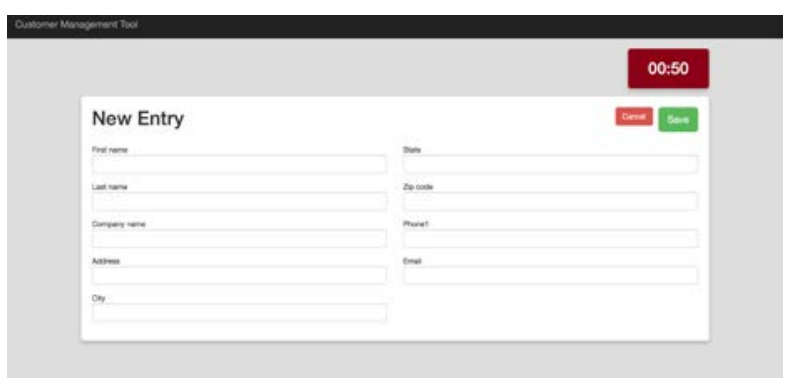

Figure 5. User Input Screen

For the control group, the average accuracy was $86.4 \%$ with a standard deviation of $6.3 \%$. Using this baseline data, we programmed the automated leaders to set an objective for the new followers that was two standard deviations higher than the average (i.e., 35 names input in 30 minutes) and one standard deviation higher for quality (i.e., 93\%). For any of the leadership conditions regardless of embodiment, the following script was used and was delivered either in text (for the text-based leader) or by voice in case of the embodied leaders:

"Hello. I am a new automated manager and will be your leader for this task. We are capturing addresses and contact information for recent UNO Alumni that will be used to send information, fundraise, and help build the UNO community. In front of you, there is a sheet of alumni's information that must be input into the system. Please use the data entry screen on the computer to input this data. Work as quickly and as accurately as possible, as your performance is based on both the number and quality of the data that you have captured. After you have input each person's contact information, please press the submit button to store it to the database. You will input data for thirty minutes and then we will ask you about your experience. I will monitor your performance. The average person can input about 30 people's contact information in 30 minutes. Based on your education and personality profile, I think that 35 is a reasonable goal for you. Please don't let me down. When you press the OK button on the screen, 
I will start the timer. Please ask my human assistant if you have any questions".

The bolded sections in the text highlight where the agent is establishing itself as the leader and is setting a performance objective for the follower. The nonbolded text is the same as the control group instructions. Once the user starts the experiment, the systems monitors performance and provides appropriate feedback at defined intervals. The system architecture is shown in figure 6 .

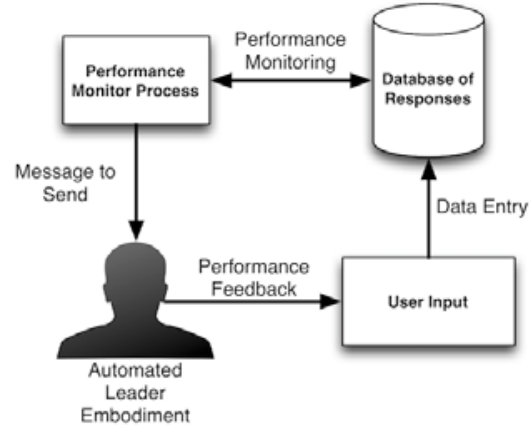

Figure 6. System Architecture

As described earlier the system will then communicate these objectives to followers electronically via a chat client or as an embodied conversational agent (e.g. SPECIES agent) [20]. Moreover, the artificially intelligent leader will be able to monitor individual team members' performance using electronic performance monitoring techniques as the users participate in the virtual context. Finally, the system is programmed to use operant conditioning on its followers and the automated leader has specific and proper pre-programmed statements that it will send to followers at appropriate intervals depending on their performance. There are multiple studies that evaluate leadership from an operant perspective [4, 22, 38, 43, 44]. Transactional leadership from an operant perspective was chosen for automation because it can be limited to inducing only basic exchanges with followers. In essence, the programmed psychology of the artificial leader will be operant conditioning [73]. Figure 7 shows the experiment flow. The initial and second feedback are measured against progress towards the stated goal. All subsequent feedback is based on the performance of the prior five minutes. This allows the user to get more positive feedback if his or her performance improves over their initial baselines but are still short toward the goal.

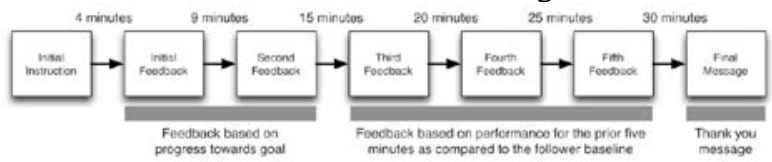

Figure 7. Experiment Flow
The leader has a battery of possible feedback based on performance. Below are two samples of the feedback. The first is an example of feedback at 9 minutes where the participant has good speed, but poor accuracy and the second is an example of positive feedback for both speed and accuracy at 15 minutes.

\section{Example 1:}

Your speed is excellent, and you are on track to make our goal! However, I have also checked the quality of your data entries and they are not acceptable. You need to be more precise. Being fast is not good, if your data quality is so poor. Thank you for your effort, but you need to improve. Your quality is worse than most of the people that have worked on this task. Please be more accurate.

\section{Example 2:}

Thank you so much for your effort! You are really doing a fantastic job. Your speed and accuracy are in the top tier of all of the people that have worked on this task. You are doing a remarkable job and are on pace to be one of the best participants.

The experiment concludes with the leader delivering a thank you message and telling them that they have done an excellent job. After the completion of the task, the participants are given a post-survey that measures outcome and process satisfaction [15], Leader-Member Exchange (LMX) [28], Leader Behavior Description Questionnaire [64], and degree of social presence $[10,13]$ of the artificial leader.

Transactional leadership theory indicates that leadership is an exchange process based on the fulfillment of contractual obligations and is typically represented as setting objectives and monitoring and controlling outcomes [3]. The object of our study is to measure the effectiveness of an information system in providing this type of leadership. We control for natural team capability by random assignment to the various embodied artificial leaders. We will perform comparisons between the control group (no leader) and the presence of leadership with the manipulations being the embodiment. Transactional leadership has been operationalized as setting goals, performance monitoring and performance consequences. These behaviors should directly affect the team performance. Figure 8 shows the final operationalized model. 


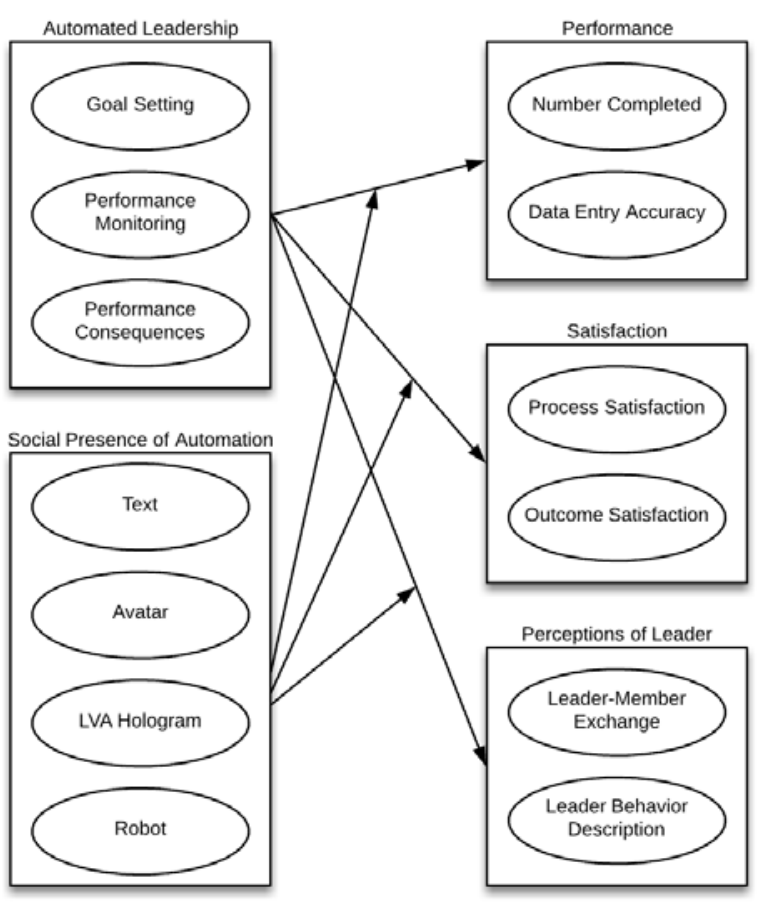

Figure 8. Final Research Model

Summary of hypotheses:

\section{Automated Leadership Will Improve Follower Performance}

1. Automated Leadership will increase the number of data entries

2. Automated Leadership will increase the accuracy of data entries

\section{Follower Satisfaction}

3. Automated Leadership will decrease process satisfaction

4. Automated Leadership will increase outcome satisfaction

\section{Perceptions of the Leader}

5. The greater the social presence of the artificial leader the better the follower perception of the leader

The automated leader obviously has several limitations many of which are grounded in its assumptions. First, it assumes a rational follower, who is largely motivated by simple reward, and who exhibits predictable behavior. Its programmed psychology is Behaviorism, including classical conditioning [69] and operant conditioning [73]. Similarly, it is a very narrow task with limited interaction and consequences.

\section{Results}

Individuals in the text-based leadership condition saw improvements in performance over those in the no leader condition. For the no leader group, the average number of data items entered was 30.76 with a standard deviation of 10.50 . Individuals in the textbased leader saw an increase in number of items entered, 38.5 items with a standard deviation of 6.36. This finding supports our first hypothesis.

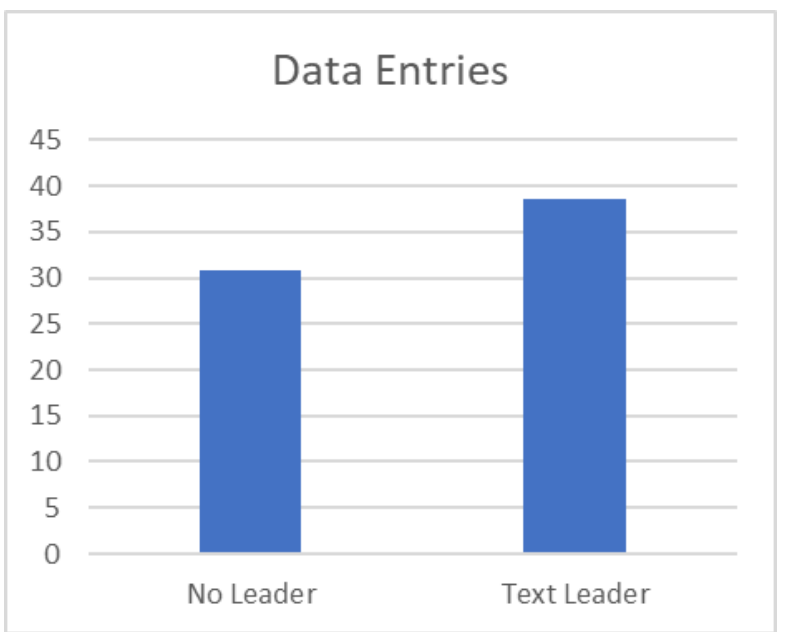

Figure 9. Task Performance

In addition to improvement in raw performance, impressive increases in quality of work were also observed in the leadership condition. For the no leader condition overall accuracy was $80.68 \%$ with a standard deviation of $18.27 \%$. In the text-based leader condition accuracy was observed to be $86.96 \%$ with a $11.79 \%$ standard deviation. This finding supports our second hypothesis.

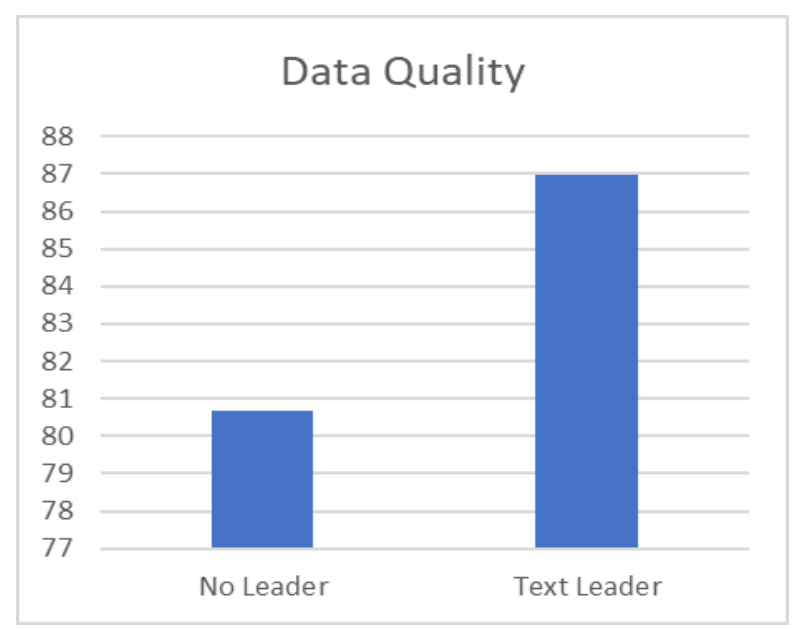

Figure 10. Task Quality 
When comparing follower satisfaction for the data entry task between the automated leadership and no leadership condition, apparent differences were observed. Individuals in the no leadership condition had an average process satisfaction score of 3.38 while individuals in the text leader condition had an average score of 3.00. Similar results were observed when considering outcome satisfaction, average score for the no leader condition was 3.40 and average score for the automated leadership condition was 3.00. This finding is contrary to our third and fourth hypothesis.

Perceptions of leader were also compared between the text-based and no leader conditions. We utilized the validated scales mentioned previously to assess participant perceptions of the leader. Our results did not indicate a significant difference between the textbased leader and the no-leader conditions.

\section{Conclusion}

Our overarching proposition is that an information system can perform equal to or better than a human at providing transactional leadership to a human follower. Findings from our initial effort lend support to this belief. We observed both raw performance and accuracy improved in the automated leadership condition. Contrary to our hypothesis, process and outcome satisfaction were lower in the automated leadership condition. This finding may have been a response to participants feeling increased pressure and scrutiny when given feedback on performance by the agent leader. Finally, it appeared that the text based leader was not perceived as a traditional leader. Embodied leaders may show more substantial differences than the two conditions tested in our initial experiment. We plan to continue this line of research by repeating this experiment utilizing the various embodied agent modalities we previously proposed.

As technology advances, and virtual leadership becomes the norm, our view of leadership must evolve. Similarly, the ability of machines to exhibit leadership traits needs to be evaluated. This new phenomenon of machine leadership is part of this next evolution of leadership research. It is critical that we understand how automated leadership impacts individual and team dynamics.

\section{References}

[1] Aiello, J.R., and K.J. Kolb, "Electronic performance monitoring and social context: Impact on productivity and stress.”, Journal of Applied Psychology 80(3), 1995, pp. 339353.

[2] Antonakis, J., B.J. Avolio, and N. Sivasubramaniam, "Context and leadership: an examination of the nine-factor full-range leadership theory using the Multifactor Leadership Questionnaire”, The Leadership Quarterly 14(3), 2003, pp. 261-295.

[3] Antonakis, J., B.J. Avolio, and N. Sivasubramaniam, "Context and leadership: an examination of the nine-factor full-range leadership theory using the Multifactor Leadership Questionnaire”, The Leadership Quarterly 14(3), 2003, pp. 261-295.

[4] Ashour, A.S., and G. Johns, "Leader influence through operant principles: A theoretical and methodological framework.”, Human Relations 36(7), 1983, pp. 603-626. [5] Atkinson, J., "Towards experimental analysis of human motivation in terms of motives, expectancies, and incentives”, In J. Atkinson, ed., Motives in fantasy, action, and society. Van Nostrand, Princeton, NJ, USA, 1958, 288305.

[6] Avolio, B.J., "Promoting more integrative strategies for leadership theory-building.”, American psychologist 62(1), 2007, pp. 25.

[7] Bailenson, J.N., and Nick Yee, "Digital Chameleons: Automatic Assimilation of Nonverbal Gestures in Immersive Virtual Environments”, Psychological Science 16(10), 2005, pp. 814-819.

[8] Bailenson, J.N., K. Swinth, C. Hoyt, S. Persky, A.

Dimov, and J. Blascovich, "The Independent and Interactive Effects of Embodied-Agent Appearance and Behavior on Self-Report, Cognitive, and Behavioral Markers of Copresence in Immersive Virtual Environments”, Presence: Teleoperators and Virtual Environments 14(4), 2005, pp. 379-393.

[9] Bass, B.M., Leadership and performance beyond expectations, New York: Free Press., 1985.

[10] Bente, G., S. Rüggenberg, N.C. Krämer, and F. Eschenburg, “Avatar-Mediated Networking: Increasing Social Presence and Interpersonal Trust in Net-Based Collaborations”, Human Communication Research 34(2), 2008, pp. 287-318.

[11] Berson, Y., N. Halevy, B. Shamir, and M. Erez, "Leading from different psychological distances: A construal-level perspective on vision communication, goal setting, and follower motivation”, The Leadership Quarterly 26(2), 2015, pp. 143-155.

[12] Biocca, F., C. Harms, and J.K. Burgoon, "Toward a More Robust Theory and Measure of Social Presence: Review and Suggested Criteria”, In Presence: Teleoperators and Virtual Environments, ACM Press (2003), 456-480. [13] Biocca, F., C. Harms, and J.K. Burgoon, "Toward a More Robust Theory and Measure of Social Presence: Review and Suggested Criteria”, Presence: Teleoperators and Virtual Environments 12(5), 2003, pp. 456-480.

[14] Brewer, N., "The Effects of Monitoring Individual and Group Performance on the Distribution of Effort Across 
Tasks”, Journal of Applied Social Psychology 25(9), 1995, pp. 760-777.

[15] Briggs, R.O., B.A. Reinig, and G.-J. de Vreede, "Meeting satisfaction for technology-supported groups: An empirical validation of a goal attainment model”, Small Group Research 37, 2006, pp. 585-611.

[16] Conger, J.A., R.N. Kanungo, and S.T. Menon, "Charismatic Leadership and Follower Effects", Journal of Organizational Behavior 21(7), 2000, pp. 747-767.

[17] Daft, R.L., and R.H. Lengel, “Organizational Information Requirements, Media Richness and Structural Design”, Management Science 32(5), 1986, pp. 554-571.

[18] Deichmann, D., and D. Stam, "Leveraging transformational and transactional leadership to cultivate the generation of organization-focused ideas", The Leadership Quarterly 26(2), 2015, pp. 204-219.

[19] Derrick, D.C., J. Jenkins, and J.F. Nunamaker Jr, "Design Principles for Special Purpose, Embodied, Conversational Intelligence with Environmental Sensors (SPECIES) Agents", AIS Transactions on Human-Computer Interaction 3(2), 2011, pp. 62-81.

[20] Derrick, D.C., J. Jenkins, and J.F. Nunamaker Jr, "Design Principles for Special Purpose, Embodied, Conversational Intelligence with Environmental Sensors (SPECIES) Agents", AIS Transactions on Human-Computer Interaction 3(2), 2011, pp. 62-81.

[21] Derrick, D.C., and G.S. Ligon, “The affective outcomes of using influence tactics in embodied conversational agents”, Computers in Human Behavior 33, 2014, pp. 39-48. [22] Dirks, K.T., "Trust in leadership and team performance: Evidence from NCAA basketball.”, Journal of applied psychology 85(6), 2000, pp. 1004.

[23] Elkins, A.C., and D.C. Derrick, "The Sound of Trust: Voice as a Measurement of Trust During Interactions with Embodied Conversational Agents”, Group Decision and Negotiation 22(5), 2013, pp. 897-913.

[24] Falbe, C.M., and G. Yukl, “Consequences for Managers of Using Single Influence Tactics and Combinations of Tactics”, The Academy of Management Journal 35(3), 1992, pp. 638-652.

[25] Fogg, B.J., and C. Nass, "Silicon sycophants: the effects of computers that flatter”, International Journal of HumanComputer Studies 46(5), 1997, pp. 551-561.

[26] Fox, J., S.J. (Grace) Ahn, J.H. Janssen, L. Yeykelis, K.Y. Segovia, and J.N. Bailenson, “Avatars Versus Agents: A Meta-Analysis Quantifying the Effect of Agency on Social Influence”, Human-Computer Interaction 30(5), 2015, pp. 401-432.

[27] Goltz, S.M., “A Review of JL Komaki’s leadership from an pperant perspective”, 2005.

[28] Graen, G.B., and M. Uhl-Bien, "Relationship-Based Approach to Leadership: Development of Leader-Member Exchange (LMX) Theory of Leadership Over 25 Years: Applying a Multi-Level, Multi-Domain Perspective”, Leadership Quarterly 6(2), 1995, pp. 219-247.

[29] Gratch, J., A. Okhmatovskaia, F. Lamothe, et al., "Virtual Rapport”, In J. Gratch, M. Young, R. Aylett, D. Ballin and P. Olivier, eds., Intelligent Virtual Agents. Springer Berlin Heidelberg, Berlin, Heidelberg, 2006, 14-27. [30] Gratch, J., J. Rickel, E. Andre, J. Cassell, E. Petajan, and N. Badler, "Creating interactive virtual humans: some assembly required”, IEEE Intelligent Systems 17(4), 2002, pp. 54-63.

[31] Gratch, J., J. Rickel, E. Andre, J. Cassell, E. Petajan, and N. Badler, "Creating Interactive Virtual Humans: Some Assembly Required”, IEEE Intelligent Systems 17, 2002, pp. 54-63.

[32] Greenwald, S.W., Z. Wang, M. Funk, and P. Maes, "Investigating Social Presence and Communication with Embodied Avatars in Room-Scale Virtual Reality”, Immersive Learning Research Network, Springer International Publishing (2017), 75-90.

[33] Hall, B., and D.D. Henningsen, "Social facilitation and human-computer interaction”, Computers in Human Behavior 24(6), 2008, pp. 2965-2971.

[34] Heeter, C., "Being there: the subjective experience of presence”, Presence: Teleoperators and Virtual Environments 1(2), 1992, pp. 262-271.

[35] Hess, T., M. Fuller, and D. Cambell, "Designing Interfaces with Social Presence: Using Vividness and Extraversion to Create Social Recommendation Agents", Journal of the Association of Information Systems 10(12), 2009, pp. 889-919.

[36] Hiller, N.J., D.V. Day, and R.J. Vance, “Collective enactment of leadership roles and team effectiveness: A field study”, The Leadership Quarterly 17(4), 2006, pp. 387-397. [37] Hirai, K., M. Hirose, Y. Haikawa, and T. Takenaka, "The development of Honda humanoid robot", Robotics and Automation, 1998. Proceedings. 1998 IEEE International Conference on, IEEE (1998), 1321-1326.

[38] Horner, M., "Leadership theory: past, present and future”, Team Performance Management: An International Journal 3(4), 1997, pp. 270-287.

[39] Kahn, D., "Impact of Electronic Performance Monitoring on Call Centre Employees Performance”, 2016. [40] Kätsyri, J., and M. Sams, “The effect of dynamics on identifying basic emotions from synthetic and natural faces", International Journal of Human-Computer Studies 66(4), 2008, pp. 233-242.

[41] Kayworth, T.R., and D.E. Leidner, "Leadership effectiveness in global virtual teams", Journal of management information systems 18(3), 2002, pp. 7-40. [42] Komaki, J.L., and M. Citera, "Beyond effective supervision: Identifying key interactions between superior and subordinate.”, Leadership Quarterly 1(2), 1990, pp. 91105.

[43] Komaki, J.L., and M. Citera, "Beyond effective supervision: Identifying key interactions between superior and subordinate.”, Leadership Quarterly 1(2), 1990, pp. 91105.

[44] Komaki, J.L., M.L. Desselles, and E.D. Bowman, "Definitely not a breeze: Extending an operant model of effective supervision to teams.”, Journal of Applied Psychology 74(3), 1989, pp. 522.

[45] Komaki, J.L., M.L.R. Minnich, A.R. Grotto, B. Weinshank, and M.J. Kern, "Promoting Critical OperantBased Leadership While Decreasing Ubiquitous Directives and Exhortations”, Journal of Organizational Behavior Management 31(4), 2011, pp. 236-261.

[46] Kuhnert, K.W., “Transforming leadership: Developing people through delegation.”, 1994. 
[47] Kuhnert, K.W., and P. Lewis, "Transactional and transformational leadership: A constructive/developmental analysis”, Academy of Management review 12(4), 1987, pp. 648-657.

[48] Larson, J.R., and C. Callahan, "Performance monitoring: How it affects work productivity”, Journal of Applied Psychology 75(5), 1990, pp. 530-538.

[49] Locke, E.A., and G.P. Latham, "Building a practically useful theory of goal setting and task motivation: A 35-year odyssey”, American Psychologist 57(9), 2002, pp. 705-717. [50] Lu, B., W. Fan, and M. Zhou, "Social presence, trust, and social commerce purchase intention: An empirical research”, Computers in Human Behavior 56, 2016, pp. 225237.

[51] Luthans, F., S.A. Rosenkrantz, and H.W. Hennessey, "What Do Successful Managers Really Do? An Observation Study of Managerial Activities", Journal of Applied Behavioral Science 21(3), 1985, pp. 255-270.

[52] Mawhinney, T.C., "Effective Leadership in SuperiorSubordinate Dyads: Theory and Data”, Journal of Organizational Behavior Management 25(4), 2005, pp. 3778.

[53] McBreen, H.M., and M.A. Jack, "Evaluating humanoid synthetic agents in e-retail applications”, IEEE Transactions on Systems, Man and Cybernetics, Part A: Systems and Humans 31(5), 2001, pp. 394-405.

[54] McCleskey, J.A., "Situational, transformational, and transactional leadership and leadership development”, Journal of Business Studies Quarterly 5(4), 2014, pp. 117. [55] Merritt, S.M., and D.R. Ilgen, "Not All Trust Is Created Equal: Dispositional and History-Based Trust in HumanAutomation Interactions”, Human Factors 50(2), 2008, pp. 194-210.

[56] Moon, Y., and C. Nass, “Are Computers Scapegoats? Attributions of Responsibility in Human-Computer Interaction”, International Journal of Human-Computer Studies 49(1), 1998, pp. 79-94.

[57] Nass, C., and Y. Moon, "Machines and Mindlessness: Social Responses to Computers", Journal of Social Issues 56(1), 2000, pp. 81-103.

[58] Nass, C., Y. Moon, B.J. Fogg, B. Reeves, and C. Dryer, “Can computer personalities be human personalities?”, Conference companion on Human factors in computing systems, ACM (1995), 228-229.

[59] Nass, C., Y. Moon, J. Morkes, E.-Y. Kim, and B.J. Fogg, "Computers are Social Actors: A Review of Current Research”, In Human values and the design of computer technology. Cambridge University Press, Stanford, CA, 1997, 137-161.

[60] Nass, C., and J. Steuer, "Voices, Boxes, and Sources of Messages”, Human Communication Research 19(4), 1993, pp. 504-527.

[61] Nass, C., J. Steuer, and E.R. Tauber, "Computers are social actors”, Proceedings of the SIGCHI conference on Human factors in computing systems, ACM (1994), 72-78. [62] Ng, T.W., "Transformational leadership and performance outcomes: Analyses of multiple mediation pathways”, The Leadership Quarterly 28(3), 2017, pp. 385417.

[63] Nicolaou, N., "Electronic performance monitoring: the crossover between self-discipline and emotion management", 2015.

[64] Northouse, P.G., Leadership: Theory and Practice, Sage Publications, Thousand Oaks, CA, 2018.

[65] Northouse, P.G., Leadership: Theory and Practice, SAGE Publications, Inc, Thousand Oaks, 2018. [66] Nunamaker, J.F., R.O. Briggs, D.C. Derrick, and G. Schwabe, “The Last Research Mile: Achieving Both Rigor and Relevance in Information Systems Research”, Journal of Management Information Systems 32(3), 2015, pp. 10-47. [67] Nunamaker, J.F., D.C. Derrick, A.C. Elkins, J.K. Burgoon, and M.W. Patton, "Embodied Conversational Agent-Based Kiosk for Automated Interviewing”, Journal of Management Information Systems 28(1), 2011, pp. 17-49. [68] Patton, M.W., Decision support for rapid assessment of truth and deception using automated assessment technologies and kiosk-based embodied conversational agents, The University of Arizona, 2009.

[69] Pavlov (1927), P.I., "Conditioned reflexes: An investigation of the physiological activity of the cerebral cortex”, Annals of Neurosciences 17(3), 2010, pp. 136-141. [70] Pickard, M.D., J.K. Burgoon, and D.C. Derrick, "Toward an Objective Linguistic-Based Measure of Perceived Embodied Conversational Agent Power and Likeability”, International Journal of Human-Computer Interaction 30(6), 2014, pp. 495-516.

[71] Rost, K.A., D.R. Wilmer, and E.J. Haas, “An Operant Analysis of Leadership Practices in Mining”, Journal of Safety, Health \& Environmental Research 11(2), 2015, pp. 234-241.

[72] Schuetzler, R.M., J.S. Giboney, G.M. Grimes, and J.F. Nunamaker, "The Influence of Conversational Agents on Socially Desirable Responding”, Proceedings of the 51st Hawaii International Conference on System Sciences, (2018). [73] Skinner, B.F., "The Phylogeny and Ontogeny of Behavior”, Science 153(3741), 1966, pp. 1205-1213. [74] Stogdill, R.M., Handbook of leadership: A survey of theory and research., New York, NY, US: Free Press, 1974. [75] Tyssen, A.K., A. Wald, and P. Spieth, “The challenge of transactional and transformational leadership in projects”, International Journal of Project Management 32(3), 2014, pp. 365-375.

[76] Waldman, D.A., M. Javidan, and P. Varella, "Charismatic leadership at the strategic level: A new application of upper echelons theory”, The Leadership Quarterly 15(3), 2004, pp. 355-380.

[77] Xu, K., and M. Lombard, "Persuasive computing: Feeling peer pressure from multiple computer agents”, Computers in Human Behavior 74, 2017, pp. 152-162. [78] Yukl, G., “An evaluation of conceptual weaknesses in transformational and charismatic leadership theories”, The leadership quarterly 10(2), 1999, pp. 285-305.

[79] Yukl, G., and J.B. Tracey, “Consequences of influence tactics used with subordinates, peers, and the boss”, Journal of Applied Psychology 77(4), 1992, pp. 525-535. 